\title{
Positive sexuality in men with spinal cord injury
}

\author{
Jean-Marc Soler ${ }^{1} \cdot$ Marie-Agnes Navaux $^{1} \cdot$ Jean-Gabriel Previnaire $^{2}$
}

Received: 20 April 2018 / Revised: 16 June 2018 / Accepted: 19 June 2018 / Published online: 2 July 2018

(c) International Spinal Cord Society 2018

\begin{abstract}
Study design Prospective study.

Objectives To analyze determinants of sexual pleasure in men with spinal cord injury (SCI).

Setting Centre Bouffard-Vercelli, Cerbere, France.

Methods Face to face interviews with men with chronic SCI who had an active sex life with a female partner, reliable erections permitting intercourse, and sought regular counselling with a sex therapist. Questionnaires: the International Index of Erectile Function (IIEF) and a modified Sexual History Form.

Results Thirty-three men were enroled. IIEF subscores were high for erectile function (mean 27.6/30), sexual desire (mean 8.8/10), intercourse satisfaction (mean 11.9/15) and overall satisfaction (mean 8.7/10). Overall satisfaction was significantly related to the level $(p<0.01)$ but not the severity of the lesion $(p=0.59)$, positively correlated with intercourse satisfaction $(p<0.001)$, negatively with age $(p<0.05)$ and age at injury $(p<0.01)$, but not with time since injury $(p=0.80)$.

Orgasm was reported by 14 men $(42 \%)$, and correlated strongly with antegrade ejaculation $(p<0.001)$, but not with overall satisfaction $(p=0.81)$. All men, except one, described enjoyable, long foreplay. Intercourse was associated with sensations of pleasure for 30 men (90\%). After intercourse, 26 men (78\%) experienced sensations of fulfilment, and $30(90 \%)$ of relaxation. Most men expressed frustration, primarily in the case of absent or intermittent ejaculation or orgasm. Men described their female partners as taking more initiatives, and having a satisfactory sex life.

Conclusions A positive and satisfying sex life is achievable by the men's willingness to adapt their sexual behaviour coupled with the reward of physical pleasure experienced during intercourse.
\end{abstract}

\section{Introduction}

Sexuality is a key element relating to quality of life in men with spinal cord injury (SCI). Recovery of sexual function is one of the highest priorities of those men [1].

While many papers have been published on the effectiveness of treatments to restore erectile function and ejaculation following SCI [2-4], pleasure, orgasm and sexual satisfaction have received little consideration [5]. Previous studies showed that relationship factors such

Electronic supplementary material The online version of this article (https://doi.org/10.1038/s41393-018-0177-9) contains supplementary material, which is available to authorized users.

Jean-Gabriel Previnaire

previnjg@hopale.com

1 Centre Bouffard-Vercelli, 66290 Cerbere, France

2 Spinal Unit, Centre Calvé, Fondation Hopale, Berck sur Mer, France as partner satisfaction and sense of intimacy, as well as mood, self-esteem and independence, were more important for men than genital function [6-10]. A recent study that sought to determine the reasons for pursuing sexual activity in both men and women with SCI, found that more than half of the subjects (58\%) reported a need for intimacy as the primary reason, followed by sexual needs (19\%), self-esteem (10\%), and to keep their partner (8\%) [11]. Concerns about bowel or bladder continence can also prevent an active sex life [11-13]. Erectile dysfunction represents a major determinant of psychological distress in this population [14]. For a long time, it was considered that sexual satisfaction in men with SCI was limited to their ability to please their sexual partner [15, 16]. However, some authors have stressed the need for a positive approach [5, 10, 17, 18], more focused on men's personal satisfaction than on any substitutes.

The aim of this study was to analyze determinants of sexual satisfaction after SCI in a selected population of men who had a regular sex life with few barriers. 


\section{Methods}

The study was conducted between January and June 2004 . Participation was proposed to men with SCI who were regularly followed up in our neurourology clinic for bladder and bowel continence, and who sought regular counselling with the sex therapist as inpatients or outpatients. The inclusion criteria were men with chronic (more than 1 year) SCI, who had an active sex life with a female partner for more than 6 months at the time of the study and had reliable erections with pharmacological treatments that allowed intercourse (involving penetration). Exclusion criteria were the presence of urinary or faecal incontinence, and recent history of depression.

Face to face interviews were conducted with a sex therapist, using the International Index of Erectile Function (IIEF) questionnaire and a specific questionnaire partly derived from the Sexual History Form (SHF) [19]. Those interviews lasted for approximately $3 \mathrm{~h}$ over one or two sessions (max 2 days interval).

- The IIEF questionnaire contains 15 questions, rated from 0 or 1 to 5, yielding an overall score of 5-75 points. The results can be regrouped into five domains (erectile function, intercourse satisfaction, orgasmic function, sexual desire and overall satisfaction). Orgasmic function is rated from the responses to two specific questions about the frequency of ejaculation (question 9) and of feeling of orgasm or climax (question 10) [20]. Erectile function is a 6-item cluster (questions 1 to 5 and question 15) yielding a global score of 30. A score of 1-10 indicates severe erectile dysfunction, 11-16 moderate dysfunction, 17-25 mild dysfunction, and greater than 25 "normal" function [21]. The questionnaire was completed by the men during the interview based on their experiences during the previous 4 weeks (not their most frequent experience [21]). The information was then corroborated by the interviewer.

- The Sexual History Form (SHF) is a questionnaire that evaluates sexual functioning including desire, arousal, orgasm, pain, frequency of sexual activities, and overall sexual satisfaction in the general population [19]. The original form consists of 28 multiple-choice items that have variable numbers of response options and different response scales. Response options are numbered and verbal descriptors of each are provided. It is also available in French (Formulaire d'Histoire Sexuelle). We altered the original SHF to make it relevant to men with SCI and sensory impairments: eight questions were removed and 20 questions were added, fitting the same multiaxial description system (desire, arousal, fantasy and imagination, orgasm, pleasure, frustration, partner orgasm and information). Questions were either open or closed using rating scales (the SHF rating method was used, with a visual analogue scale (VAS), or yes/no answers) (see Appendix).

- All the questions were asked by the sex therapist. During the interview, orgasm was defined as a transient feeling of intense pleasure that is accompanied by an altered state of consciousness. Other sensations (happiness, fulfilment...) were discussed with the patients without specific definitions.

\section{Statistics}

Data were analyzed using R 3.1.1 Development Core Team Software (R, Vienna, Austria). The men were categorized into two groups: orgasm and no orgasm. Chi-squared or Fisher's exact tests were used to compare values of qualitative variables and ANOVA was used for variables with normal or approximately normal distributions. Correlations between variables were analyzed using Pearson's or Spearman's methods, as appropriate; $p<0.05$ was considered significant for all analyses.

\section{Statement of ethics}

We certify that all applicable institutional and governmental regulations concerning the ethical use of human volunteers were followed during the course of this research.

Table 1 Population characteristics

\begin{tabular}{llllll}
\hline & Level & Severity (AIS) & Type & Age (years) & Time injury (years) \\
\hline Orgasm $n=14$ & $\begin{array}{l}7 \text { tetraplegia, 6 paraplegia, } \\
1 \text { cauda equina }\end{array}$ & A: 10 B: 3 C: 1 & UMN: 13 LMN: 1 & $39.8(9.3)[26.4-59.5]$ & $17.0(10.1)[1.0-31.6]$ \\
No orgasm $n=19$ & $\begin{array}{l}8 \text { tetraplegia, 9 paraplegia, } \\
2 \text { cauda equina }\end{array}$ & A: 13 B: 6 & UMN: 17 LMN: 2 & $38.8(12.5)[22.0-60.2]$ & $9.7(8.3)[1.1-26.7]$ \\
Total sample $n=33$ & NS $(p=0.65)$ & NS $(p=0.60)$ & NS $(p=0.74)$ & NS $(p=0.81)$ & S $(p<0.05)$ \\
\hline
\end{tabular}

Values for age and time since injury are given as means (standard deviations); [minima and maxima]

AIS ASIA Impairment Scale, $U M N$ upper motor neuron, $L M N$ lower motor neuron, $S$ significant, $N S$ not significant 


\section{Results}

Fifty-eight men were asked to participate in the study. Twenty-five of them did not want to take part, mainly due to a lack of time or interest. The characteristics of the 33 participants are presented in Table 1. Mean age was $39.2 \pm 11.1$ years and mean time since injury was $12.8 \pm 9.7$ years. Fifteen men had tetraplegia, 15 paraplegia and three had cauda equina lesions. Most men had complete motor lesions (ASIA Impairment Scale (AIS) A or $\mathrm{B}, n=32$ ) and upper motor neuron lesions (UMN, $n=30$ ). All men regularly used pharmacological treatments to enhance their erections, either oral Sildenafil $(n=29)$ or intracavernosal injections of prostaglandin E1 $(n=4)$. All men had new partners since the SCI. Fourteen men (42\%) experienced orgasms, while $19(58 \%)$ did not. Orgasm was significantly related to time since injury $(p<0.05)$ but not to age $(p=0.81)$, lesion level $(p=0.65)$, type $(p=0.60)$ or severity $(p=0.74)$.

\section{IIEF results}

Thirteen men in the orgasm group (93\%) reported experiencing orgasm sometimes (about half the time) or most times (much more than half the time), only one man always experienced orgasm. Ejaculation was reported by 13 men, 12 of whom were in the orgasm group (eight sometimes, three most times and one almost always or always). Orgasm correlated strongly with ejaculation $(r=0.9$, $p<0.001)$ : only one man had ejaculation without orgasm, and two had orgasm without ejaculation. There were no correlations between orgasm and erectile function $(p=0.18)$, sexual desire $(p=0.81)$, intercourse satisfaction $(0.91)$ or overall satisfaction $(p=0.81)$ (Table 2$)$.

With their usual pharmacological treatments, 28 men had erectile function scores between 26 and 30 (no erectile dysfunction), four had scores between 17 and 25 (mild erectile dysfunction), and one had a score between 6 and 10 (severe erectile dysfunction); four of the five men with mild to severe erectile dysfunction were in the no orgasm group. Erectile function significantly correlated with intercourse satisfaction $(r=0.4, p<0.05)$, but not with overall satisfaction $(p=0.11)$.
Sexual desire was high or very high in 31 men, but very low in two. Sexual intercourse was considered as highly or very highly enjoyable by 28 men, but not enjoyable by two (both in the no orgasm group).

Most men reported high levels of intercourse satisfaction (scores 11-15: $n=26$ ) and overall satisfaction (scores 8-10: $n=28$ ). Overall satisfaction was significantly related to the level (tetraplegia: mean 9.3; paraplegia: mean 8.5; cauda equina: mean 6.3) $(p<0.01)$ but not to the severity $(p=0.59)$ of the lesion, positively correlated with intercourse satisfaction $(r=0.8, p<0.001)$, negatively with age $(r=-0.4, p<0.05)$ and age at injury $(r=-0.5$, $p<0.01)$, and was not correlated with time since injury $(p=0.80)$. Sexual desire correlated with intercourse satisfaction $(r=0.7, p<0.001)$ and overall satisfaction $(r=0.6$, $p<0.001)$.

\section{Modified SHF Questionnaire}

\section{Desire, foreplay, arousal and intercourse}

The frequency of sexual intercourse was around twice a week. The majority of men would have liked to have sexual intercourse 3 or 4 times a week. Most men initiated sexual intercourse $(94 \%)$. All men usually responded to their partners' sexual advances. Sexual desire was experienced 3 to 4 times a week. Duration of foreplay (kissing, petting, hugging, etc.) was usually between 16 and $30 \mathrm{~min}$, although 14 men reported durations of more than $30 \mathrm{~min}$. All men described feelings of arousal (pleasure, excitement, "being turned on") more than $75 \%$ of the time. Vision during foreplay or penetration was important to enhance pleasure and excitement for the majority of men. Fantasies were regularly used by $54 \%$ of men to increase arousal. Fourteen men, including nine with tetraplegia, described intense pleasure during caresses over the whole body, even on insensate skin. Many men with complete lesions also described pleasure during oral sex (fellatio). All but one man described a high level of pleasure during foreplay (Table 3). In most cases, the female partner took more initiatives and assumed a more active sexual role to compensate for the physical barriers imposed by the SCI.

Table 2 IIEF results

\begin{tabular}{lllllll}
\hline & Orgasm & Ejaculation & Erectile Function & Sexual Desire & Intercourse Satisfaction & Overall Satisfaction \\
& Q 10 $(0-10$ scale $)$ & Q 9 $(0-5$ scale $)$ & Q 1 to 5, 15 $(1-30$ scale $)$ & Q 11-12 (2-10 scale) & Q 6 to $8(0-15$ scale $)$ & Q 13-14 (2-10 scale) \\
\hline Orgasm $n=14$ & $3.4(0.6)[3-5]$ & $3.1(1.1)[1-5]$ & $28.9(2.7)[20-24,26-31]$ & $8.9(1.0)[7-10]$ & $12.1(1.9)[9-14]$ & $8.9(1.2)[7-10]$ \\
No orgasm $n=19$ & $1.0(0)[1]$ & $1.2(0.7)[1-4]$ & $26.7(6.2)[8-24,26-31]$ & $8.7(1.7)[4-10]$ & $11.7(2.9)[4-15]$ & $8.6(1.9)[3-10]$ \\
Total sample $n=33$ & $\mathrm{~S}(p<0.001)$ & $\mathrm{S}(p<0.001)$ & NS $(p=0.22)$ & NS $(p=0.82)$ & NS $(p=0.65)$ & NS $(p=0.63)$ \\
\hline
\end{tabular}

Values are given as means (standard deviations); [minima and maxima]

$I I E F$ International Index of Erectile Function, $S$ significant, $N S$ not significant 
Table 3 Modified SHF Questionnaire (Pleasure, Orgasm \& Frustration)

\begin{tabular}{lllllllll}
\hline & $\begin{array}{l}\text { Pleasure } \\
\text { foreplay }\end{array}$ & $\begin{array}{l}\text { Pleasure } \\
\text { coitus }\end{array}$ & Ejaculation Happiness & Relaxation & $\begin{array}{l}\text { Maximum } \\
\text { pleasure }\end{array}$ & $\begin{array}{l}\text { Partner satisfaction } \\
(0-6 \text { scale })\end{array}$ & $\begin{array}{l}\text { Men frustration } \\
(0-3 \text { scale })\end{array}$ \\
\hline Orgasm $n=14$ & Yes: 14 No: & Yes: 14 & Yes: 12 & Yes: 13 & Yes: 14 & Self: 8 & $5.4(0.6)[4-6]$ & $1.6(0.8)[1-3]$ \\
& 0 & No: 0 & No: 2 & No: 1 & No: 0 & Partner: 6 & & \\
No orgasm $n$ & Yes: 18 No: & Yes: 16 & Yes: 1 No: Yes: 13 & Yes: 16 & Self: 7 & $5.5(1.0)[2-6]$ & $2.1(0.9)[0-3]$ \\
$=19$ & 1 & No: 3 & 18 & No: 6 & No: 3 & Partner: 12 & & \\
Total sample $n$ & NS $(p=$ & NS $(p=$ & S $(p<$ & NS $(p=$ & NS $(p=$ & NS $(p=0.25)$ & NS $(p=0.59)$ & NS $(p=0.15)$ \\
$=33$ & $0.38)$ & $0.12)$ & $0.001)$ & $0.09)$ & $0.12)$ & & & \\
\hline
\end{tabular}

Values are given as means (standard deviations); [minima and maxima]

$S H F$ Sexual History Form, $S$ significant, $N S$ not significant

Duration of intercourse (penetration) was usually between 20 and $30 \mathrm{~min}$, although 16 men reported intercourse that lasted for more than $30 \mathrm{~min}$. Thirty men described sensations of pleasure during intercourse, which were very intense for 18; three men never experienced these feelings (one with tetraplegia, one with high and one with low paraplegia) (Table 3 ).

There were no statistical differences between the groups with and without orgasm for any of these data.

\section{Orgasm}

Fourteen men (42\%) experienced orgasm: 12 during ejaculation and two without ejaculation. Ten of these men (eight of whom ejaculated) described signs of autonomic dysreflexia and increased spasms during the orgasm. Orgasm was followed by a feeling of well-being and fulfilment, and alleviation of spasticity that could last a few hours. Two men reported the symptoms of autonomic dysreflexia as very uncomfortable or painful, with pounding headaches and increased spasms accompanying ejaculation.

After intercourse, 26 men experienced sensations of happiness or fulfilment, and 30 described a sensation of relaxation.

The men's perception of their female partners' sexual satisfaction was that it was moderately to extremely high. They all achieved vaginal lubrication. One man perceived his partner's sex life as moderately unsatisfactory, and another reported she did not have orgasms. For 18 men, to please their partner was considered as more satisfying than their own pleasure, particularly in the no orgasm group, although the difference was not significant.

\section{Other considerations}

Sexual frustration was reported as moderate, with a nonsignificant trend towards higher frustration in men with no orgasm. Men related this frustration mainly to absent or intermittent ejaculation or orgasm, and secondarily to their lack of autonomy (Table 3).
All men had received information and/or counselling regarding sexual activity following the SCI, as a routine component of rehabilitation in our centre. Since all men had changed or met new partners after SCI, the women had not attended the educational workshops on sexuality provided during the rehabilitation process. The new partners had never attended consultations with the sex therapist, for personal reasons. Twenty-four men (74\%) reported that their partners were highly informed (based on their own communication of information to their partners).

All men, without exception, reported that they had adapted their sexual activity after the SCI.

\section{Discussion}

The main determinants of a positive sex life were the willingness of the men to adapt their sexual life, and the experience of physical pleasure during foreplay and intercourse (through reliable erections). Physical and emotional aspects likely interacted, reinforcing desire and increasing the intimacy of the relationship. A shift of roles occurred, with the female partners playing a more active role in sexual activity. We feel that orgasm, which occurred mainly in men who ejaculated, could be interpreted as a reward.

\section{Foreplay, intercourse and desire}

Former studies have shown that foreplay plays an important role in the sex life of men with SCI: hugging, kissing, caressing, oral sex, visual aids or fantasy are commonly practiced. However, in those studies, foreplay was mainly practiced or encouraged as a substitute for intercourse $[6,7,9,22-25]$. This study confirmed that the majority of men enjoyed lengthy foreplay, and that it increased their arousal. Furthermore, many men reported enjoying being caressed over the whole body, even on insensate skin and men with complete lesions reported that 
their genitals could be sexually aroused by caresses or fellatio, as already reported by Alexander [6]. Pleasurable foreplay helps create a more intimate relationship $[7,8,11$, $15,16,26]$.

Rigid erections allow men to be more sexually active and to engage in intercourse [27], and can also improve ejaculation frequency [4], intercourse satisfaction [7, 12], and quality of life [28]. With appropriate pharmacological treatments, $84 \%$ of the men in this study were able to have reliable erections. Strikingly, most men reported pleasure during coitus. A possible explanation for this is that recovery of sexual capacity and potency helps them regain a sense of masculinity, allowing them to engage in intercourse if they wished to, as "normal men" would do [22]. For these men, intercourse was clearly not limited to the gratification of their partner after SCI, as has previously been reported $[6,8-10,16]$.

The interview revealed that the couples adapted their sexual activity to their new boundaries, with the female partners assuming a more active sexual role, taking more initiatives and widening the sexual repertoire. The men were more passive but could still satisfy their partners through foreplay and vaginal penetration. Men with SCI have been said to be more attentive lovers, truly interested in providing pleasure to their female partners [29].

Most men reported a high level of sexual desire, which is in line with most studies in the chronic phase of SCI [5, 10, 23, 30, 31]. Interestingly, we found a significant correlation between sexual desire and intercourse satisfaction or overall satisfaction which might indicate that the pleasure received during foreplay and coitus provides a physical and/or emotional pay-off of being sexually active, which in turn increased desire [6, 24, 30].

\section{Orgasm, autonomic dysreflexia, relief of spasticity, fulfilment}

Forty-two percent of the men in this study reported experiencing orgasm, in particular those men who had antegrade ejaculation. These results are consistent with the literature, which reports that around $40 \%$ of men with SCI experience orgasm of a similar, weaker, or different quality than pre-injury $[2,5,6,15]$. Orgasm is strongly related to antegrade ejaculation, either during sexual intercourse [6] or through penile vibratory stimulation [25]. In contrast with many studies [6, 24, 25], we found no effect of level, type or severity of the lesions on orgasm; however, one other study also reported no relationship with lesion severity [31]. Time since injury, but not age, significantly improved the chances of orgasm [32]. Orgasm can occur in men with SCI who do not ejaculate $[6,25,33]$, as was the case for two men in the present study. Interestingly, there was no correlation between orgasm and sexual satisfaction, as has been shown previously [30]. Orgasm is likely a combination of a genitally, reflex-based component and non-genital components that may play larger, compensatory roles when the reflex component is impaired [24]. A sense of frustration still prevailed in most men, related either to the absence of orgasm in the no orgasm group, or to the lack of reliable ejaculation and/or orgasm in the other group. Achieving reliable orgasm after SCI is definitely a bonus for these men [24].

Ejaculation was accompanied by clinical symptoms of autonomic dysreflexia in 10 men, two of whom reported these symptoms as very unpleasant. Autonomic dysreflexia is a common finding in men with SCI above T6, it often occurs during sexual activity, and can have both negative and positive consequences [24, 34, 35]. Negative signs include pounding headaches, discomfort, nausea, painful spasms, sweating and an increase in blood pressure that can be harmful [35]. On the other hand, it has been shown that with time and experience, men may incorporate the physiological signs of autonomic dysreflexia as a positive aspect of sexual activity, and learn to interpret them as sexually enhancing [11, 24, 36, 37]. Some authors have hypothesized that sensory substitution could be utilized to maximize sexual pleasure and orgasm through repetitive training [38].

Ten men reported a decrease in spasticity after ejaculation and orgasm. This anti-spastic effect has been reported following penile vibratory stimulation and can last for up to 3 $\mathrm{h}$. It is more pronounced if antegrade ejaculation occurs [39]. Most men also described a sense of fulfilment and relaxation after intercourse, even if ejaculation or orgasm did not occur. This is probably similar to the resolution phase of sex during which muscles relax, blood pressure drops and the body slows down from its excited state, a normal component of the human sexual response cycle.

\section{Sexual satisfaction}

Sexual satisfaction was high in the men included in this study, in strong contrast with most studies $[6,8,9,13,16$, $23,31,40-42]$. One explanation is that the participants in this study shared specific characteristics: in addition to having reliable erections, they sought regular counselling with a sex therapist, and showed a willingness to adapt their social and sexual lives. Most had chosen a partner after the SCI with whom they seemed to have developed open communication regarding their sexuality. Most importantly, they developed other aspects of sexuality such as intimacy and emotional sharing, which are major components of the adaptation to their new sexual lives, as has been shown in other studies $[7,11,15,16,22,26$, $40,43]$. It has also been found that living with a stable partner in an enduring relationship [10, 13, 15, 16] or 
having multiple partners [6] increases sexual satisfaction. Open communication can help to broaden the sexual experience through experimenting with alternative sexual expressions $[8,26]$. We feel that the physical pleasure experienced by men during foreplay and intercourse, sometimes with the added reward of an orgasm, could be considered as a further physical component that motivated adaptation. Positive physical and emotional experiences helped to boost the men's sexual desire and self-esteem. Sexual satisfaction and quality of life have been shown to interact and reinforce one another [7, 10, $44,45]$. The correlation between sexual satisfaction and intercourse satisfaction further indicates that restoring reliable erections is an important step in the sexual rehabilitation process [12, 24].

\section{Other aspects}

Young age has been shown to positively influence sexual adjustment. Young people with SCI seem to have a higher degree of motivation and greater ability to redefine sexual goals and expectations [8, 10], as well as being more sexually active [12]. Satisfaction with sex life improves with time [16, 23, 41], and time also allows couples to adjust to the physical impairments and compensatory behaviour imposed by SCI [40]. While our results confirmed the relationship between younger age at injury and sexual satisfaction, we found no effect of time since injury, probably because this time was longer than in other studies $(12.8 \pm 9.7$ years). Our results are in agreement with other studies, showing no effect of level and severity of lesion on sexual satisfaction $[8,10,13,27,31]$, and also highlight the poorer satisfaction of men with a cauda equina syndrome and lower motor neuron lesions [13, 33, 46].

All men had attended an inpatient program for sexual rehabilitation and were followed by a sex therapist as outpatients. Counselling and education about the consequences of spinal cord damage on sexuality is of paramount importance and helps men adjust to their new sexual capacities [6, 10, 47-49].

Finally, the IIEF is frequently used as an outcome measure in clinical trials [20], but has been rarely used in men with SCI $[4,12,14,21,28]$, although it is recommended by the Committee for the Measurement of Sexual Functioning after SCI for this population [21]. There is a need for specific tools to measure other aspects of sexual function, including satisfaction, in men with SCI.

\section{Limitations}

We selected participants with few barriers to sexual activity, and the high rate of orgasm (42\%) found in this study is probably the highest that can be achieved with currently available treatments. Midodrine, which increases the rate of ejaculation and orgasm with penile vibratory stimulation [3, 25], has a high rate of effectiveness; however, its use is restricted to clinical settings to control the risk of autonomic dysreflexia [24].

In France, the social security system provides free access to treatment for incontinence (including botulinum toxin) and some treatments for erectile dysfunction (intracavernous injections of prostaglandin), although some phosphodiesterase inhibitors (Sildenafil, Tadalafil) must be paid for by the individual (3 euros on prescription). Therefore, cost of treatment is likely a smaller barrier to sexual activity than in other countries.

Access to a sex therapist is often another barrier, either because of a lack of availability of therapists, or because men do not perceive the potential benefits for themselves. In our centre, consultations are freely available and systematically proposed; however, only a few men (roughly $10 \%)$ seek sexual guidance.

Finally, we believe the results of this study conducted in 2004 are still relevant today. There have not been any major changes in the treatment of either erectile dysfunction or incontinence over the last decade. However, the social environment is fast changing, and the extensive use of social media certainly changes the ways in which romantic or sexual encounters can occur [47]. Research is needed to determine if social networking helps to raise barriers for men with SCI to meet potential sexual partners.

\section{Conclusion}

The results of this study showed that men with SCI can live a positive sex life. This can be done through comprehensive application of the principles of sexual rehabilitation: [5, 47] adapt to their residual limitations by utilizing specialized therapies, encourage them to maximize the remaining capacities of the whole body, and to motivate them to stay open to rehabilitative efforts and new forms of sexual stimulation. It is the role of the medical and paramedical team to facilitate men's willingness through educational programs during the acute phase of the SCI, and via counselling with sex therapists thereafter.

More research is still needed to improve current treatments for erectile and ejaculatory dysfunction so that men can count on reliable erections during sexual activity at home.

Acknowledgements We are grateful to Dr. Vincke Bernard for statistical assistance, and to Johanna Robertson for revision of the English. 
Author contributions JMS, MAN and JGP were responsible for designing and writing the protocol, for extracting and analyzing the data. They all contributed to writing the report. MAN conducted the interviews.

\section{Compliance with ethical standards}

Conflict of interest The authors declare that they have no conflict of interest.

\section{References}

1. Anderson KD. Targeting recovery: priorities of the spinal cordinjured population. J Neurotrauma. 2004;21:1371-83.

2. Biering-Sørensen F, Alexander MS, Elliott S, Popolo GD, Previnaire JG, Velez AR. Sexuality and fertility management. In: Chhabra HS, editor. ISCoS text book on comprehensive management of spinal cord injuries. India: Wolters Kluwer; 2015. p. 613-35.

3. Soler JM, Previnaire JG, Plante P, Denys P, Chartier-Kastler E. Midodrine improves ejaculation in spinal cord injured men. J Urol. 2007;178:2082-6.

4. Soler JM, Previnaire JG, Denys P, Chartier-Kastler E. Phosphodiesterase inhibitors in the treatment of erectile dysfunction in spinal cord-injured men. Spinal Cord. 2007;45:169-73.

5. Elliott S. Ejaculation and orgasm: sexuality in men with SCI. Top Spinal Cord Inj Rehabil. 2002;8:1-15.

6. Alexander CJ, Sipski ML, Findley TW. Sexual activities, desire, and satisfaction in males pre- and post-spinal cord injury. Arch Sex Behav. 1993;22:217-28.

7. Kreuter M, Sullivan M, Siosteen A. Sexual adjustment after spinal cord injury (SCI) focusing on partner experiences. Paraplegia. 1994;32:225-35.

8. Kreuter M, Sullivan M, Siosteen A. Sexual adjustment and quality of relationship in spinal paraplegia: a controlled study. Arch Phys Med Rehabil. 1996;77:541-8.

9. Reitz A, Tobe V, Knapp PA, Schurch B. Impact of spinal cord injury on sexual health and quality of life. Int $\mathrm{J}$ Impot Res. 2004; 16:167-74.

10. Siosteen A, Lundqvist C, Blomstrand C, Sullivan L, Sullivan M. Sexual ability, activity, attitudes and satisfaction as part of adjustment in spinal cord-injured subjects. Paraplegia. 1990;28: 285-95.

11. Anderson KD, Borisoff JF, Johnson RD, Stiens SA, Elliott SL. The impact of spinal cord injury on sexual function: concerns of the general population. Spinal Cord. 2007;45:328-37.

12. Gomes CM, Miranda EP, de Bessa J Jr., Bellucci CHS, Battistella LR, Abdo CHN, et al. Erectile function predicts sexual satisfaction in men with spinal cord injury. Sex Med. 2017;5: e148-e55

13. Valtonen K, Karlsson AK, Siosteen A, Dahlof LG, Viikari-Juntura E. Satisfaction with sexual life among persons with traumatic spinal cord injury and meningomyelocele. Disabil Rehabil. 2006;28: 965-76.

14. Barbonetti A, Cavallo F, Felzani G, Francavilla S, Francavilla F. Erectile dysfunction is the main determinant of psychological distress in men with spinal cord injury. J Sex Med. 2012;9:830-6.

15. Phelps J, Albo M, Dunn K, Joseph A. Spinal cord injury and sexuality in married or partnered men: activities, function, needs, and predictors of sexual adjustment. Arch Sex Behav. 2001;30: 591-602.

16. White MJ, Rintala DH, Hart KA, Young ME, Fuhrer MJ. Sexual activities, concerns and interests of men with spinal cord injury. Am J Phys Med Rehabil. 1992;71:225-31.
17. Ducharme SH, Gill KM. Sexuality After Spinal Cord Injury: Answers to Your Questions.. Baltimore: Paul H Brookes; 1997.

18. Alexander M. Sexual sustainability: a guide to having a great sex life with a spinal cord disorder. Kindle edition; Amazon Digital Services LLC 2017.

19. Schover LR, Friedman JM, Weiler SJ, Heiman JR, LoPiccolo J. Multiaxial problem-oriented system for sexual dysfunctions: an alternative to DSM-III. Arch Gen Psychiatry. 1982;39: 614-9.

20. Rosen RC, Riley A, Wagner G, Osterloh IH, Kirkpatrick J, Mishra A. The international index of erectile function (IIEF): a multidimensional scale for assessment of erectile dysfunction. Urology. 1997;49:822-30.

21. Alexander MS, Brackett NL, Bodner D, Elliott S, Jackson A, Sonksen J, et al. Measurement of sexual functioning after spinal cord injury: preferred instruments. J Spinal Cord Med. 2009;32: 226-36.

22. Burns SM, Mahalik JR, Hough S, Greenwell AR. Adjustment to changes in sexual functioning following spinal cord injury: the contribution of men's adherence to scripts for sexual potency. Sex Disabil. 2008;26:197-205.

23. Fisher TL, Laud PW, Byfield MG, Brown TT, Hayat MJ, Fiedler IG. Sexual health after spinal cord injury: a longitudinal study. Arch Phys Med Rehabil. 2002;83:1043-51.

24. Elliott SL. Problems of sexual function after spinal cord injury. Prog Brain Res. 2006;152:387-99.

25. Soler JM, Previnaire JG, Plante P, Denys P, Chartier-Kastler E. Midodrine improves orgasm in spinal cord-injured men: the effects of autonomic stimulation. J Sex Med. 2008;5:2935-41.

26. Seddon M, Warren N, New PW, 'I don't get a climax anymore at all': pleasure and non-traumatic spinal cord damage. Sexualities. 2017. https://doi.org/10.1177/1363460716688681:1-16.

27. Biering-Sorensen I, Hansen RB, Biering-Sorensen F. Sexual function in a traumatic spinal cord injured population 10-45 years after injury. J Rehabil Med. 2012;44:926-31.

28. Hultling C, Giuliano F, Quirk F, Pena B, Mishra A, Smith MD. Quality of life in patients with spinal cord injury receiving Viagra (sildenafil citrate) for the treatment of erectile dysfunction. Spinal Cord. 2000;38:363-70.

29. Trieschmann RB. Sexual harmony despite impotence. In: Leyson JFJ, editor. Sexual rehabilitation of the spinal-cord-injured patient. New York: Springer; 1991. p. 233-50.

30. Cardoso FL, Savall AC, Mendes AK. Self-awareness of the male sexual response after spinal cord injury. Int J Rehabil Res. 2009;32:294-300.

31. Dahlberg A, Alaranta HT, Kautiainen H, Kotila M. Sexual activity and satisfaction in men with traumatic spinal cord lesion. J Rehabil Med. 2007;39:152-5.

32. Teppers MS. Lived experiences that impede or facilitate sexual pleasure and orgasm in people with spinal cord injury. Philadelphia: University of Pennsylvania; 2001.

33. Sipski M, Alexander CJ, Gomez-Marin O. Effects of level and degree of spinal cord injury on male orgasm. Spinal Cord. 2006;44:798-804.

34. Alexander MS, Biering-Sorensen F, Bodner D, Brackett NL, Cardenas D, Charlifue S, et al. International standards to document remaining autonomic function after spinal cord injury. Spinal Cord. 2009;47:36-43.

35. Davidson R, Elliott $S$, Krassioukov A. Cardiovascular responses to sexual activity in able-bodied individuals and those living with spinal cord injury. J Neurotrauma. 2016;33:2161-74.

36. Courtois F, Charvier K, Vezina JG, Journel NM, Carrier S, Jacquemin G, et al. Assessing and conceptualizing orgasm after a spinal cord injury. BJU Int. 2011;108:1624-33. 
37. Courtois F, Charvier K, Leriche A, Vezina JG, Cote I, Raymond $\mathrm{D}$, et al. Perceived physiological and orgasmic sensations at ejaculation in spinal cord injured men. J Sex Med. 2008;5: 2419-30.

38. Borisoff JF, Elliott SL, Hocaloski S, Birch GE. The development of a sensory substitution system for the sexual rehabilitation of men with chronic spinal cord injury. J Sex Med. 2010;7:3647-58.

39. Laessoe L, Nielsen JB, Biering-Sorensen F, Sonksen J. Antispastic effect of penile vibration in men with spinal cord lesion. Arch Phys Med Rehabil. 2004;85:919-24.

40. McCabe MP, Taleporos G. Sexual esteem, sexual satisfaction, and sexual behavior among people with physical disability. Arch Sex Behav. 2003;32:359-69.

41. Mendes AK, Cardoso FL, Savall AC. Sexual satisfaction in people with spinal cord injury. Sex Disabil. 2008;26:137-47.

42. Scholten EWM, Tromp MEH, Hillebregt CF, de Groot S, Ketelaar M, Visser-Meily JMA, et al. Mental health and life satisfaction of individuals with spinal cord injury and their partners 5 years after discharge from first inpatient rehabilitation. Spinal Cord. 2018;56:598-606.

43. Hess MJ, Hough S. Impact of spinal cord injury on sexuality: broad-based clinical practice intervention and practical application. J Spinal Cord Med. 2012;35:211-8.
44. Cobo Cuenca AI, Sampietro-Crespo A, Virseda-Chamorro M, Martin-Espinosa N. Psychological impact and sexual dysfunction in men with and without spinal cord injury. J Sex Med. 2015;12: 436-44.

45. Kreuter M, Sullivan M, Dahllof AG, Siosteen A. Partner relationships, functioning, mood and global quality of life in persons with spinal cord injury and traumatic brain injury. Spinal Cord. 1998;36:252-61.

46. Previnaire JG, Soler JM, Alexander MS, Courtois F, Elliott S, McLain A. Prediction of sexual function following spinal cord injury: a case series. Spinal Cord Ser Cases. 2017;3:17096.

47. Elliott S, Hocaloski S, Carlson M. A multidisciplinary approach to sexual and fertility rehabilitation: the sexual rehabilitation framework. Top Spinal Cord Inj Rehabil. 2017;23:49-56.

48. New PW, Seddon M, Redpath C, Currie KE, Warren N. Recommendations for spinal rehabilitation professionals regarding sexual education needs and preferences of people with spinal cord dysfunction: a mixed-methods study. Spinal Cord. 2016;54: 1203-9.

49. Alexander MS, Alexander CJ. Recommendations for discussing sexuality after spinal cord injury/dysfunction in children, adolescents, and adults. J Spinal Cord Med. 2007;30 Suppl 1: S65-70. 